Termination of early human pregnancy with RU 486 (mifepristone) and the prostaglandin analogue sulprostone: a multicentre, randomized comparison between two treatment regimens. Hum Reprod 1989;4:718-25.

7 World Health Organisation. Pregnancy termination with mifepristone and gemeprost: a multicentre comparison between repeated doses and a single dose of mifepristone. Fertil Steril 1991;56:32-40.

8 Rodger MW, Baird DT. Induction of therapeutic abortion in early pregnancy with mifepristone in combination with prostaglandin pessary. Lamce 1987;ii:1415-8.
9 Swahn ML, Ugocsai G, Bygdeman M, Kovaks L, Belsey EM, Van Look PFA. Effect of oral prostaglandin $E_{2}$ on uterine contractility and treatmen outcome in women receiving RU 486 (mifepristone) for termination of early pregnancy. Hum Reprod 1989;4:21-8.

10 Thong KJ, Baird DT. Induction of abortion with mifepristone and misoprostol in early pregnancy. Br 7 Obstet Gymaecol 1992;99:1004-7.
Fourth Department of Medicine, University of Erlangen-Nürnberg, 90429 Nürnberg, Germany Roland E Schmieder assistant professor of internal medicine

Christoph Gatzka resident Hans Schobel resident

\section{Department of}

Psychosomatic Medicine, St Franziska Stift, 6550 Bad Kreuznach, Germany Heinz Rüddel assistant professor of psychosomatic medicine

Hartmut Schächinger, resident

Correspondence and requests for reprints to: Dr Schmieder.

\title{
Obesity as a determinant for response to antihypertensive treatment
}

\author{
Roland E Schmieder, Christoph Gatzka, Hartmut Schächinger, Hans Schobel, Heinz Rüddel
}

Abstract

Objective-To test the hypothesis that $\beta$ blockers lower blood pressure more effectively than calcium entry blockers in obese hypertensive patients and that calcium entry blockers are more effective in lean patients.

Design-Double blind, randomised controlled trial of treatment over six weeks.

Setting-Tertiary referral centre.

Subjects-42 white men with uncomplicated mild to moderate essential hypertension (World Health Organisation stage I or II); 36 completed the study.

Intervention-Patients were randomised to metoprolol 50-100 mg twice daily or isradipine $2 \cdot 5-$ $5.0 \mathrm{mg}$ twice daily for six weeks after a two week run in phase.

Main outcome measure-Blood pressure after six weeks of treatment.

Results-When stratified according to treatment and presence of obesity (body mass index $<$ or $\geqslant 27$ $\mathrm{kg} / \mathrm{m}^{2}$ ), the mean (SD) fall in blood pressure in the $\beta$ blocker group was 24 (13)/18 (10) $\mathrm{mm} \mathrm{Hg}$ in obese patients and $18(19) / 12(13) \mathrm{mm} \mathrm{Hg}$ in lean patients. In the calcium entry blocker group, the fall in blood pressure was $21(15) / 17$ (6) $\mathrm{mm} \mathrm{Hg}$ in lean patients and $18(11) / 8(10) \mathrm{mm} \mathrm{Hg}$ in obese patients. After taking age and blood pressure before treatment into account there was a significant interaction between obesity and drug therapy $(p=0.019)$ with a better diastolic blood pressure response to calcium entry blockers in lean patients and to $\beta$ blockers in obese hypertensive patients.

Conclusion-Obesity affects the efficacy of metoprolol and isradipine in reducing blood pressure.

\section{Introduction}

Large scale prospective studies have shown that antihypertensive drugs prevent cardiovascular morbidity and reduce cardiovascular mortality. ${ }^{1} \beta$ Blockers and calcium entry blockers are both recommended as first line treatment for hypertension ${ }^{2}$ but there are no guidelines about which drugs lower blood pressure most effectively in patients with uncomplicated essential hypertension. Age has been claimed to be an important predictor of response to antihypertensive drugs, but other studies have not confirmed this initial hypothesis or its clinical implications. ${ }^{4}$ Obesity, which is present in more than half of hypertensive patients, has been neglected as a potential determinant of response to treatment. ${ }^{2}$

Obesity has a major influence on the haemodynamic changes associated with hypertension. ${ }^{5}$ Several studies indicate that obese hypertensive patients have a higher cardiac output and lower total peripheral resistance than lean patients at any given level of arterial hypertension. ${ }^{67}$ Obese hypertensive patients seem to have increased sympathetic activity, which may be reduced with weight loss. ${ }^{8}$ Different haemodynamic patterns in hypertensive patients have been suggested to be clinically relevant for treating hypertensive patients.9 We therefore tested the hypothesis that a $\beta$ blocker is more effective than a calcium entry blocker in obese patients and that a calcium entry blocker is more effective than a $\beta$ blocker in lean patients. We reasoned that the putatively hyperdynamic circulation of obese patients would respond better to $\beta$ blockade and that the increased peripheral vascular resistance in lean hypertensive patients might respond better to the smooth muscle relaxing effects of a calcium entry blocking drug. ${ }^{10-12}$

\section{Subjects and methods}

Patients referred to our hospital because of arterial hypertension were consecutively enrolled if they fulfilled all the study criteria. All patients were white men with mild to moderate essential hypertension who met World Health Organisation stage I or II criteria. Patients with secondary causes of arterial hypertension, congestive heart failure, clinical or electrocardiographic signs of coronary heart disease, second or third degree atrioventricular block, or concomitant diseases such as chronic obstructive lung disease, renal insufficiency, haematological diseases, or other conditions that could influence the resorption or metabolism of calcium entry blockers or $\beta$ blockers, were excluded from the study.

In the single blind run in all subjects were given placebo for two weeks as a wash out. No other drugs were permitted throughout the whole study. To qualify for entry in the double blind treatment the patient's diastolic blood pressure had to be 95-109 $\mathrm{mm} \mathrm{Hg}$ on two occasions during the wash out phase. All blood pressure measurements (before and during therapy) were obtained after the patient had rested for five minutes in a seated position. The people measuring blood pressure had been trained to use the mercury column sphygmomanometer. The appropriate cuff size to account for obesity was used. Forty two patients fulfilled the blood pressure criteria after the two week run in phase. Their mean (SD) casual blood pressure was $162(12) / 103(8) \mathrm{mm} \mathrm{Hg}$ and their mean age was 49 (12) years.

After the run in phase patients were randomly assigned to treatment with either the calcium entry blocker isradipine $2.5 \mathrm{mg}$ twice daily $(n=20)$, or $\beta$ blocker metoprolol $50 \mathrm{mg}$ twice daily $(n=22)$. If the diastolic blood pressure was more than $90 \mathrm{~mm} \mathrm{Hg}$ after three weeks of treatment the dose was doubled. This was the case in seven patients randomised to receive $\beta$ blockers and in six patients randomised to calcium entry blockers. Patients received no dietary guidelines (sodium restriction, weight loss programmes) throughout the study period. Blood pressure was monitored for six weeks. After six weeks venous blood samples were taken from each patient to measure serum concentration of the drug. Patients were unaware that blood was 
to be taken. No drug was detected in blood from one patient in the isradipine group and from five patients in the metoprolol group. These six patients were excluded from the statistical analysis (non-compliant patients). None of the patients was lost to follow up and no serious side effects were encountered.

The protocol was approved by the institutional committee on human subjects. Written, informed consent was obtained from each patient before the run in phase.

The results were analysed on an IBM 308-1 computer system with the SPSS-X statistical program..$^{13}$ Thirty six patients were entered in the data analysis. They were stratified according to treatment and according to absence or presence of obesity. Subjects were classified as lean if their body mass index ranged was $19-27 \mathrm{~kg} / \mathrm{m}^{2}$ and as obese if body mass index was greater than $27 \mathrm{~kg} /$ $\mathrm{m}^{2}$. The cut off point of $27 \mathrm{~kg} / \mathrm{m}^{2}$ was chosen according to the results of the National Center for Health Statistics survey. ${ }^{14}$ Furthermore $27 \mathrm{~kg} / \mathrm{m}^{2}$ corresponds closely to the criterion for obesity suggested in the 1983 Metropolitan Life Insurance tables ( $>20 \%$ over desirable weight for people of medium build).${ }^{15}$ Analysis of variance was used to compare the response after six weeks of treatment, with age and systolic and diastolic blood pressure before treatment as cofactors. Unless otherwise specified, the data are expressed as mean (SD).

\section{Results}

Patients in the two treatment groups did not differ in age $(47$ (10) in $\beta$ blocker group $v 50$ (11) years in calcium entry blocker group), heart rate (79 (8) $v 77$ (7) beats $/ \mathrm{min}$ ), and blood pressure before treatment (161 (8)/104 (7) v $162(14) / 102$ (7) $\mathrm{mm} \mathrm{Hg}$ ). Furthermore,

TABLE I-Clinical characteristics in the four groups stratified according to drug treatment and body mass index

\begin{tabular}{|c|c|c|c|c|c|}
\hline & \multicolumn{2}{|c|}{ B Blocker group (metoprolol) } & \multicolumn{2}{|c|}{$\begin{array}{c}\text { Calcium entry blocker group } \\
\text { (isradipine) }\end{array}$} & \multirow[b]{2}{*}{$\mathrm{p}$ Valu } \\
\hline & Lean $(n=7)$ & Obese $(n=10)$ & Lean $(n=11)$ & Obese $(n=8)$ & \\
\hline Body mass index $\left(\mathrm{kg} / \mathrm{m}^{2}\right)$ & $25 \cdot 2(9)$ & $30.4(2.4) \dagger$ & $24 \cdot 3(0.9) \dagger$ & $31 \cdot 3(2 \cdot 4) \dagger$ & $t<0.001$ \\
\hline Age (years) & $49(8)$ & $45(12)$ & 49 (11) & $51(12)$ & NS \\
\hline Height $(\mathrm{cm})$ & $173(6)$ & $178(9)$ & $177(7)$ & $175(4)$ & NS \\
\hline \multicolumn{6}{|l|}{ Weight (kg): } \\
\hline Before treatment & $75(9)$ & $97(9) t$ & $76(7)$ & $97(9) \dagger$ & $<0.001$ \\
\hline After treatment & $74(9)$ & $97(8) \dagger$ & $75(8)$ & $97(9) \dagger$ & $<0.001$ \\
\hline \multicolumn{6}{|l|}{ Before treatment: } \\
\hline Systolic pressure (mm Hg) & $161(10)$ & $161(6)$ & $162(16)$ & $163(12)$ & NS \\
\hline Diastolic pressure (mm Hg) & $104(6)$ & $105(9)$ & $102(6)$ & $102(8)$ & NS \\
\hline Heart rate (beats/min) & $79(5)$ & 77 (12) & $72(7)$ & $82(7)$ & NS \\
\hline \multicolumn{6}{|l|}{ After six weeks: } \\
\hline Systolic pressure $(\mathrm{mm} \mathrm{Hg})$ & $142(17)$ & $137(14)$ & $141(10)$ & $145(7)$ & NS \\
\hline Diastolic pressure ( $\mathrm{mm} \mathrm{Hg}$ ) & $91(14)$ & 87 (11) & $85(9)$ & 94 (11) & NS \\
\hline Heart rate (beats/min) & $69(12)^{\star}$ & $69(4)^{\star}$ & $70(7)$ & $86(8)$ & $<0.01$ \\
\hline
\end{tabular}

${ }^{\star} \mathrm{p}<0.05 \beta$ blockers $v$ calcium entry blockers. $\quad$ tp $<0.01$ obese $v$ lean.

TABLE II-Fall in diastolic blood pressure ( $\mathrm{mm} \mathrm{Hg}$ ) after six weeks of treatment according to drug treatment and body mass index $\left(\mathrm{kg} / \mathrm{m}^{2}\right)$

\begin{tabular}{|c|c|c|c|c|}
\hline & \multicolumn{2}{|c|}{$\beta$ Blocker } & \multicolumn{2}{|c|}{ Calcium entry blocker } \\
\hline & $\begin{array}{c}\text { Mean (SD) } \\
\text { diastolic pressure } \\
(\mathrm{mm} \mathrm{Hg})\end{array}$ & $\begin{array}{l}95 \% \text { Confidence } \\
\text { interval }\end{array}$ & $\begin{array}{c}\text { Mean (SD) } \\
\text { diastolic pressure } \\
(\mathrm{mm} \mathrm{Hg})\end{array}$ & $\begin{array}{l}\text { 95\% Confidence } \\
\text { interval }\end{array}$ \\
\hline $\begin{array}{l}\text { Lean }\left(\leqslant 27 \mathrm{~kg} / \mathrm{m}^{2}\right) \\
\text { Obese }\left(>27 \mathrm{~kg} / \mathrm{m}^{2}\right)\end{array}$ & $\begin{array}{l}12 \cdot 4(13 \cdot 4) \\
17 \cdot 6(9 \cdot 6)\end{array}$ & $\begin{array}{r}2 \cdot 7 \text { to } 22 \cdot 1 \\
11 \cdot 8 \text { to } 23 \cdot 4\end{array}$ & $\begin{array}{l}17 \cdot 3(6 \cdot 4) \\
7 \cdot 9(10 \cdot 1)\end{array}$ & $\begin{array}{r}12.5 \text { to } 21 \cdot 1 \\
1.0 \text { to } 14.9\end{array}$ \\
\hline
\end{tabular}

Two way interaction of obesity and drug therapy, $\mathrm{p}=0.019$

TABLE II-Fall in systolic blood pressure ( $\mathrm{mm} \mathrm{Hg}$ ) after six weeks of treatment according to drug treatment and body mass index $\left(\mathrm{kg} / \mathrm{m}^{2}\right)$

\begin{tabular}{|c|c|c|c|c|}
\hline & \multicolumn{2}{|c|}{ B Blocker } & \multicolumn{2}{|c|}{ Calcium entry blocker } \\
\hline & $\begin{array}{c}\text { Mean (SD) } \\
\text { systolic pressure } \\
(\mathrm{mm} \mathrm{Hg})\end{array}$ & $\begin{array}{c}95 \% \text { Confidence } \\
\text { interval }\end{array}$ & $\begin{array}{c}\text { Mean (SD) } \\
\text { systolic pressure } \\
(\mathrm{mm} \mathrm{Hg})\end{array}$ & $\begin{array}{l}95 \% \text { Confidence } \\
\text { interval }\end{array}$ \\
\hline $\begin{array}{l}\text { Lean }\left(\leqslant 27 \mathrm{~kg} / \mathrm{m}^{2}\right) \\
\text { Obese }\left(>27 \mathrm{~kg} / \mathrm{m}^{2}\right)\end{array}$ & $\begin{array}{l}18 \cdot 3(19 \cdot 4) \\
24 \cdot 0(12 \cdot 5)\end{array}$ & $\begin{array}{r}4.3 \text { to } 32 \cdot 3 \\
16 \cdot 3 \text { to } 31.6\end{array}$ & $\begin{array}{l}20 \cdot 8(15 \cdot 4) \\
18 \cdot 2(11 \cdot 0)\end{array}$ & $\begin{array}{l}11.7 \text { to } 29.9 \\
10.5 \text { to } 25.9\end{array}$ \\
\hline
\end{tabular}

Two way interaction of obesity and drug therapy, NS. when both treatment groups were stratified into lean and obese groups, the four patient groups were similar with respect to age and blood pressure before treatment, both of which can influence the decrease in blood pressure in response to antihypertensive treatment (table I). No significant change in weight was observed in any of the four groups throughout the study period of six weeks (table I).

In the whole study group blood pressure decreased from $162(12) / 103$ (7) $\mathrm{mm} \mathrm{Hg}$ to 141 (12)/89 (11) $\mathrm{mm}$ $\mathrm{Hg}$ after six weeks of treatment $(\mathrm{p}<0.01)$. In the six non-compliant patients blood pressure fell from 160 (11)/104 (8) $\mathrm{mm} \mathrm{Hg}$ to 150 (12)/97 (10) $\mathrm{mm} \mathrm{Hg}$ $(\mathrm{p}<0.05)$. Blood pressure decreased by $22(15) / 15$ (11) $\mathrm{mm} \mathrm{Hg}(\mathrm{p}<0.01)$ in the $\beta$ blocker group and by 20 (14)/ 13 (10) $\mathrm{mm} \mathrm{Hg}(\mathrm{p}<0.01)$ in the calcium entry group. The decrease in blood pressure was similar in both treatment arms. Heart rate was significantly reduced after treatment with the $\beta$ blocker $(p<0.05)$ but increased in obese patients receiving isradipine (table I).

We subsequently analysed the impact of obesity and drug therapy and potential interactions between these two factors, taking into account age and blood pressure before treatment. There was no significant difference in the fall in diastolic blood pressure between lean and obese patients $(13.3 v 15.4 \mathrm{~mm} \mathrm{Hg} ; F=0.05, \mathrm{NS})$ or between patients receiving the calcium entry blocker and those receiving $\beta$ blocker $(13.4 v 15.5 ; F=0.6$, NS). In contrast, we observed a significant interaction between obesity and drug therapy. $\beta$ Blockers produced a greater decrease in diastolic blood pressure in obese patients than in lean patients and calcium entry blockers produced a greater fall in lean than obese patients $(F=6 \cdot 2, \mathrm{p}=0.019)$ (table II). Age $(F=0 \cdot 3, \mathrm{NS})$ and systolic $(F=0 \cdot 1, \mathrm{NS})$ and diastolic blood pressure $(F=1 \cdot 6, \mathrm{NS})$ before treatment had no effect on the results.

When the analysis was repeated for blood pressure after treatment (absolute values, table I) we again found a significant interaction between obesity and treatment $(F=4.8, \mathrm{p}<0.046)$. Diastolic blood pressure after treatment was lower in the lean group receiving calcium entry blockers and in the obese group receiving $\beta$ blockers than in the obese group receiving calcium entry blockers and the lean group receiving $\beta$ blockers. Thus, the type of drug given to lean or obese hypertensive patients determined the antihypertensive response in diastolic blood pressure after six weeks.

We repeated the analysis of covariance for the fall in systolic blood pressure. The decrease in systolic blood pressure was similar in the lean and obese subjects $(20.1 v 21.4 \mathrm{~mm} \mathrm{Hg}$, NS) (table III) and in the $\beta$ blocker and calcium entry blocker groups (19.7 $v 21.9$ $\mathrm{mm} \mathrm{Hg}$, NS). There was no significant interaction between obesity and drug treatment but a similar trend towards a greater decrease in systolic blood pressure in obese patients given the $\beta$ blocker and lean patients given the calcium entry blocker was suggested by the data (table I and III). Of note, systolic blood pressure before treatment had a strong impact on the decrease in systolic blood pressure $(F=17 \cdot 0, \mathrm{p}<0.001)$, whereas age $(F=0.8, \mathrm{NS})$ and diastolic blood pressure before treatment $(F=1 \cdot 1, \mathrm{NS})$ had no effect on the decrease in systolic blood pressure. Thus, the main determinant for the antihypertensive response in systolic blood pressure after six weeks was systolic blood pressure before treatment and not the interaction between obesity and drug treatment.

\section{Discussion}

PREDICTTVE VALUE OF OBESITY

We studied the question whether obesity influences the antihypertensive response to treatment with $\beta$ 
blocker or calcium entry blockers. We found that the decrease in diastolic blood pressure was more pronounced in obese hypertensive patients receiving the $\beta$ blocker metoprolol than in those receiving the calcium entry blocker isradipine. In lean patients isradipine was more effective than metoprolol at reducing blood pressure. This significant interaction between body weight and drug treatment was masked behind the fact that neither obesity nor drug therapy alone emerged as determinants for the decrease in diastolic blood pressure with treatment.

Studies examining the antihypertensive response to drugs suggested age, ${ }^{34}$ several humoral factors, ${ }^{16}{ }^{17}$ or sodium excretion ${ }^{18}$ as potential determinants for the fall in blood pressure with treatment. However, these studies did not discuss the effect of obesity. ${ }^{219}$ Several classes of antihypertensive drugs have been suggested to be particularly effective in obese patients, including sympatholytic agents, calcium entry blockers, and converting enzyme inhibitors. ${ }^{80}$ Controlled trials have been performed in groups of obese subjects. Clonidine was found to be less efficacious than the hydrochlorothiazide. ${ }^{21}$ But in another study clonidine was compared with placebo in obese patients and was found to effectively lower both blood pressure and plasma noradrenaline concentrations. ${ }^{8}$

We randomised obese and lean hypertensive patients to receive either a $\beta$ blocker or a calcium entry blocker and were thus able to test for interactions not only related to drug effect but also related to the presence or absence of obesity. Our data suggested that the likelihood of good blood pressure control was increased when metoprolol was given to obese patients and isradipine to lean patients. The large standard deviation in lean patients given $\beta$ blocker and obese patients given calcium entry blocker suggests that the individual response to treatment was highly variable.

\section{LIMITATIONS OF THE STUDY}

Certain critical points of our study need to be addressed to facilitate the interpretation of our results. We included only a small number of subjects, but this limitation is counterbalanced to a degree by the double blind, randomised controlled design. We were also able to determine drug compliance accurately by measuring drug serum concentrations. Whether different pharmacokinetic properties (for instance distribution volume) of the drugs have affected our results remains unknown. Nevertheless serum drug concentrations are only poorly related to the antihypertensive effects of antihypertensive drugs. ${ }^{22}$

By randomising and enrolling only patients with uncomplicated mild to moderate essential hypertension we obtained four groups of subjects that were similar in age and in blood pressure before treatment. Both age and blood pressure are potential determinants of the response to antihypertensive treatment. ${ }^{34}$ The effects on blood pressure were assessed after six weeks of treatment, with a single titration of dose at about

\section{Clinical implications}

- Obese patients with hypertension have high cardiac output and low total peripheral resistance

- This study showed that obesity is a determinant of the initial antihypertensive response to drugs independent of age and blood pressure before treatment

- In obese hypertensive patients $\beta$ blockers reduced high blood pressure more effectively than calcium entry blockers did

- In lean hypertensive patients calcium entry blockers controlled high blood pressure better than $\beta$ blockers did

- Obesity should be considered when deciding on treatment for hypertension three weeks. We cannot predict whether the interaction between drug treatment and obesity would be still evident after longer treatment.

Finally, our data cannot necessarily be applied to all $\beta$ blockers and all calcium entry blockers. We chose metoprolol and isradipine as representative compounds of their drug class, recognising that metoprolol is cardioselective and that isradipine has a very high affinity for voltage dependent calcium channels in vascular smooth muscle cells. Non-selective $\beta$ blockers, with or without intrinsic sympathomimetic activity, and non-dihydropyridine calcium entry blockers may have different actions in obese and lean hypertensive patients from the drugs studied here.

\section{PATHOPHYSIOLOGICAL BACKGROUND}

What could be the pathogenetic link explaining the greater effectiveness in reducing blood pressure of $\beta$ blockers in obese patients and calcium entry blockers in lean patients? Haemodynamically, hypertension is characterised by a progressive increase in total peripheral resistance. ${ }^{2324}$ This process, which reflects structural and functional changes in the vascular tree, is modified if obesity coexists. The sympathetic nervous system seems to play a substantial part in the development of hypertension in obese patients. ${ }^{8526} \mathrm{At}$ any given level of arterial hypertension obese patients have a higher cardiac output and lower total peripheral resistance than lean patients. ${ }^{67}$ This disparate haemodynamic pattern is in accord with differences observed between the haemodynamic profiles of $\beta$ blockers and calcium entry blockers. ${ }^{10-12}$ Calcium entry blockers, particularly those with high affinity for smooth muscle, clearly reduce total peripheral resistance by vasodilation. $\beta$ Blockers, on the other hand, act by reducing cardiac output. This haemodynamic action could be documented during mental stress and isometric exercise even six months after starting drug treatment. ${ }^{27} 28$ These pharmacological differences in the two drugs could at least partly explain the results that we observed.

\section{CONCLUSIONS}

In summary, our study showed that obesity influenced the efficacy of certain antihypertensive drugs. The $\beta$ blocker metoprolol lowered blood pressure more effectively in obese patients, while the calcium entry blocker isradipine was more effective in lean patients. More clinical studies will be needed to confirm our findings and extend these observations to other hypertensive drugs. Such studies are necessary to provide general guidelines for rational treatment of hypertension.

We thank Friedrich C Luft for critical review of this manuscript.

1 Collins R, Peto R, MacMahon S, Herbert P, Fiebach NH, Eberlein KA, et al. Blood pressure, stroke and coronary heart disease. Short-term reductions in blood pressure: overview of randomized drug trials in their epidemiological context. Lancet 1990;335:827-38.

2 Joint National Committee. The 1988 report of the joint national committee on detection, evaluation, and treatment for high blood pressure. Arch Interm Med 1988;148:1023-38.

3 Bühler FR. Antihypertensive treatment according to age, plasma renin and race. Drugs 1988;35:495-503.

4 Kaplan NM. Calcium entry blockers in the treatment of hypertension. Current studies and future prospects. FAMA 1989;262:817-23.

5 Messerli FH. Cardiopathy of obesity -a not so-Victorian disease. $N$ Engl fMed 1986;314:378-80.

6 Messerli FH, Sundgaard-Riise K, Reisin ED, Dreslinski G, Dunn FG, Frohlich ED. Disparate cardiovascular effects of obesity and arterial hypertension. Am F Med 1983;74:808-12.

7 Messerli FH, Sundgaard-Riise K, Reisin ED, Dreslinski GR, Ventura HO, Oigman W, et al. Dimorphic cardiac adaptation to obesity and arterial hypertension. Ann Intern Med 1983;99:757-61.

8 Tuck ML. Obesity, the sympathetic nervous system, and essential hypertension. Hypertension 1992;19(suppl 1):I-67-77.

9 Julius S. Are different hemodynamic patterns of antihypertensive drugs clinically important? Eur f Clin Pharmacol 1990;38:S125-8.

10 Messerli FH, Oren S, Grossmann E. Effects of calcium channel blockers on 
systemic hemodynamics in hypertension. Am f Med 1988;84(suppl 3B): 8-12.

11 Jespersen LT, Kruseil LR, Sihm J, Pedersen OL Differential effects of isradipine and atenolol on peripheral hemodynamics and arterial compliance. Am 7 Med 1989;86(suppl 4A):57-9.

12 Man in't Veld $A J$ Schalekamp MADH. How intrinsic sympathomimetic 12. Min in't Veld AJ Sche activity modulates the haemodynamic responses to beta-adrenoceptor ancagonists: clue to the nature of their

13 SPSS Inc. SPSS-X User's Guide. 3rd ed. Chicago: SPSS, 1988.

14 National Center for Health Statistics. Hypertension in adults 25-74 years of age. Hyattsville, Maryland: NCHS, 1971-5.

15 Metropolitan Life Insurance Company. Metropolitan height and weight tables. Stat Bull Metrop Insur Co 1984;64:2-9.

16 Erne P, Bolli P, Bartel O, Kiowski W, Buhler FR. Factors influencing the hypotensive effects of calcium antagonists. Hypertension 1983;5(suppl 2):97102.

17 Kusaka M, Ataraski K, Matsumoto K, Sumida Y, Matsuura H, Shingu T, et al. Plasma renin activity and norepinephrine as predictors for antihypertensive effects of nifedipine and captopril. Am 3 Hyperens 1991;4:735-9.

18 Nicholson JP, Rennick LM, Laragh JH. The antihypertensive effect of verapamil at extremes of dietary sodium intake. Ann Intern Med 1987;107: 329-34.

19 Freis ED, Reda DJ, Materson BJ. Volume (weight) loss and blood pressure response following thiazide diuretics. Hypertension 1988;12:244-80.
20 Frohlich ED. Obesity hypertension: converting enzyme inhibitors and calcium antagonists. Hypertension 1992;19(suppl 1):I-119-23.

21 Reisin E, Weed SG. Diuretics: a rational pharmacological approach for the treatment of obese hypertensives [abstract]. Hypertension 1991;17:405.

22 Messerli FH. Candiovascular drug therapy. Philadelphia: Saunders, 1990.

23 Folkow B. Physiological aspects of primary hypertension. Physiol Rev 1982;62:347-504.

24 Koren MJ, Savage DD, Laragh JH, Devereux RB. Relation of hemodynamic parameters to prognosis in essential hypertension [abstract]. Am o Hypertens 1990;3:13a.

25 Tuck ML, Sowers JR, Domfield L, Whitfield L, Maxwell M. Reductions in plasma catecholamines and blood pressure during weight loss in obese subjects. Acta Endocrinol 1983;102:252-7.

26 Sowers JR, Whitfield LA, Catania RA, Stern N, Tuck MI, Dornfeld L, et al. Role of the sympathetic nervous system in blood pressure maintenance in obesity. F Clin Endacrind Metabol 1982;54:1181-7.

27 Schulte W, Rüddel H, Schăchinger H, Schmieder R. The efficacy of calcium antagonists and beta blockers on the hemodynamic response to stress. Eur Heart $f$ (in press).

28 Schmieder R, Rüddel H, Neus H, Messerli FH, von Eiff AW. Disparate hemodynamic responses to mental challenge after antihypertensive therapy with betablockers and calcium entry blockers. Am fMed 1987;82:11-6.

(Accepted 22 Fune 1993)

\section{Kidney granuloma in Crohn's disease}

\section{A J Archimandritis, M S Weetch}

Gastrointestinal Centre, Southern General Hospital, Glasgow G51 4TF

A J Archimandritis, honorary registrar in gastroenterology MS Weetch, registrar in gastroenterology

Correspondence to:

Dr A J Archimandritis, University of Athens Medical School, 6 Zachou Street, Athens 11527 , Greece.

BMY 1993;307:540-1

Renal biopsy specimen from patient with Crohn's disease showing interstitial nephritis with local periglomerulofibrosis and granuloma formation (arrow) (haematoxylin and eosin)
Granulomas may be found in various tissues and organs of patients with Crohn's disease, such as lymph nodes, mesentery, peritoneum, liver, and lung and occasionally bones, joints, and skeletal muscle. ${ }^{12}$ We report an unusual case of Crohn's disease with granuloma formation in the kidneys.

\section{Case report}

A 22 year old man was admitted with episodic bloody diarrhoea, lassitude, anorexia, and weight loss over one year. BCG vaccination had been carried out in childhood; his grandmother had had Crohn's disease. Physical examination gave normal results, but his blood urea concentration was raised $(10.0 \mathrm{mmol} / \mathrm{h})$ and creatinine clearance reduced ( $44 \mathrm{ml} / \mathrm{min})$. A chest $x$ ray film, intravenous pyelogram, a barium meal and follow through examination, and a barium enema all gave negative results. On sigmoidoscopy patchy friability of the mucosa and discrete aphthoid ulcerations were found. A biopsy specimen showed an abnormal mucosa with severe inflammatory changes and fissuring; lymphocyte aggregations and sarcoid follicles were present in the submucosa. Crohn's disease was diagnosed and the patient treated with sulphasalazine and corticosteroids. Four weeks later he was symptom free; sigmoidoscopy showed an almost normal mucosa, but his blood urea concentration remained raised (12.0 mmol/ $/$ ).

During the next six months the disease relapsed twice. On the second occasion a rectal biopsy speci-

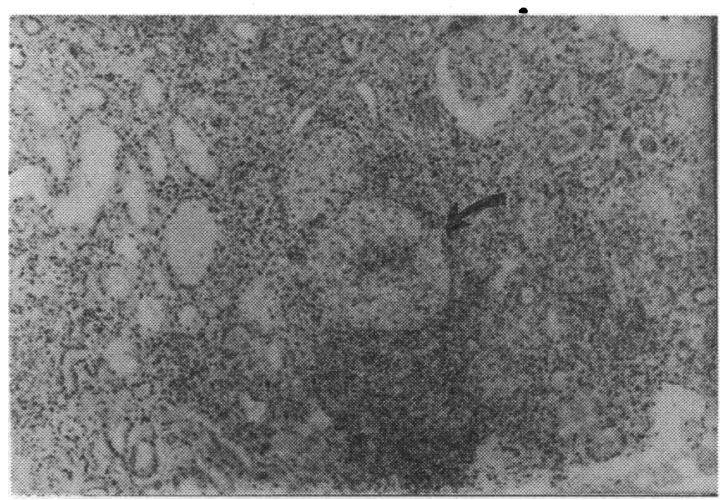

men showed granulomas. Barium enema disclosed severe abnormalities in the caecum and ascending colon that were compatible with Crohn's disease.

Dramatic improvement followed treatment with sulphasalazine and oral corticosteroids. A year later there was a further relapse, but no improvement was observed despite administration of corticosteroids in high dosage. Barium enema showed that nearly all of the colon was affected. Serum alkaline phosphatase activity was 18.8 units (King-Armstrong method) and a liver biopsy specimen showed pericholangitis. His blood urea concentration ranged from $10.0 \mathrm{mmol} / \mathrm{l}$ to $16.6 \mathrm{mmol} / \mathrm{h}$, and creatinine clearance was further reduced to $14-15 \mathrm{ml} / \mathrm{min}$. A renal biopsy specimen showed chronic interstitial nephritis with local periglomerulofibrosis and granuloma formation (figure). A chest $x$ ray film was normal; no tubercle bacilli were present in the urine. A Kveim test gave negative results, and the results of brucella serology were also negative. The patient's condition progressively deteriorated, with a rise in blood urea concentration to $19.9 \mathrm{mmol} / \mathrm{l}$. Proctocolectomy was performed. He had an uneventful recovery and was discharged in good general condition without needing to be prescribed drugs.

Four years later he was still in remission with no specific treatment. His blood urea concentration had fallen to $9.1 \mathrm{mmol} / \mathrm{h}$ and his creatinine clearance increased to $29 \mathrm{ml} / \mathrm{min}$. A second renal biopsy specimen showed mesangial prominence, loss and atrophy of renal tubules, and local interstitial fibrosis; no granulomas were found.

\section{Comment}

Liver granulomas occur in about $9.5 \%$ of patients with Crohn's disease, ${ }^{1}$ although clinically overt liver involvement does not seem to be present in more than $2 \%$ of patients. ${ }^{3}$ To our knowledge, the presence of renal granulomas in patients with Crohn's disease has not been described before. It should be pointed out that granuloma formation in the kidneys is uncommon but may occur in tuberculosis, sarcoidosis, brucellosis, Wegener's granulomatosis, xanthogranulomatous pyelonephritis, malacoplakia, leprosy, and toxoplasmosis and as an adverse reaction to various drugs. ${ }^{45}$

In our case all these causes of granuloma formation could reasonably be excluded from the patient's history; sulphasalazine, which may cause many untoward reactions such as haemolytic anaemia, temporal arteritis, and systemic lupus erythromatosus, was used only after the renal impairment was discovered. In addition, the beneficial effect of proctocolectomy on renal function and the disappearance of 